\title{
Expression analyses of Brachiaria brizantha genes encoding ribosomal proteins BbrizRPS8, BbrizRPS15a, and BbrizRPL41 during development of ovaries and anthers
}

\author{
Ana Luiza Machado Lacerda • Diva Maria de Alencar Dusi • \\ Elizangela Ribeiro Alves • Júlio Carlyle Macedo Rodrigues • \\ Ana Cristina Menezes Mendes Gomes • \\ Vera Tavares de Campos Carneiro
}

Received: 30 April 2012 / Accepted: 10 July 2012 / Published online: 26 July 2012

(C) Springer-Verlag 2012

\begin{abstract}
Brachiaria brizantha is a forage grass of the Poaceae family. Introduced from Africa, it is largely used for beef cattle production in Brazil. Brachiaria reproduces sexually or asexually by apomixis, and development of biotechnological tools for gene transfer is being researched to support the breeding programs. The molecular bases of reproduction have not yet been fully elucidated; it is known that gametophyte formation and main reproductive events occur inside the anthers and ovaries. There is therefore much interest in identifying genes expressed in these organs and their corresponding upstream regulatory sequences. In this work we characterized three cDNA from ovaries of $B$. brizantha plants (CL 09, CL10, and CL21) which show similarity in databases with genes encoding ribosomal proteins S8, S15a, and L41 and were named BbrizRPS8, BbrizRPS15a, and BbrizRPL41, respectively. These clones show higher expression in ovaries, anthers and roots, mitotically active tissues, when compared to leaves of $B$. brizantha. Localization of transcripts of BbrizRPS8, BbrizRPS15a,
\end{abstract}

Handling Editor: Klaus Harter

A. L. M. Lacerda • D. M. de Alencar Dusi • E. R. Alves • J. C. M. Rodrigues - A. C. M. M. Gomes

V. T. de Campos Carneiro

Embrapa Genetic Resources and Biotechnology,

Parque Estação Biológica (PqEB),

Av. W5 Norte (final), PO Box 02372, 70770917 Brasília,

Federal District, Brazil

A. L. M. Lacerda • D. M. de Alencar Dusi • E. R. Alves •

J. C. M. Rodrigues - A. C. M. M. Gomes •

V. T. de Campos Carneiro $(\square)$

Department of Cell Biology, University of Brasília (UnB),

Campus Universitário Darcy Ribeiro, Asa Norte,

70919970 Brasília, Federal District, Brazil

e-mail: vera.carneiro@embrapa.br and BbrizRPL41 was investigated in the reproductive organs, ovaries, and anthers, from the beginning of development up to maturity. Their activity was higher in early stages of anther development, while expression was detected in all developmental stages in the ovaries, except for BbrizS15a, which was detected only in synergids of apomictic plants.

Keywords Brachiaria brizantha · Embryo sac · Reproductive organs $\cdot$ Ribosomal proteins $\cdot$ Synergids

\section{Introduction}

Brachiaria is a genus of the Poaceae family introduced to South America from Africa in the eighteenth century (Renvoize et al. 1996), with about 100 species described in tropical and subtropical regions (Miles et al. 1996). Brachiaria brizantha is a forage grass of economic importance for cattle production in Brazil (Araújo et al. 2008), an important beef exporter (CREMAQ 2010). Brachiaria breeding is limited by the mode of reproduction of the plants and differences in ploidy levels (Miles et al. 1996). Normally, sexual plants are diploid while apomictic ones are tetraploid and hybridization strategies to introduce new characteristics are limited (Valle et al. 2004). Apomixis is an asexual mode of reproduction through seeds (Nogler 1984).

Due to the need to reveal more about apomixis, Brachiaria is an important system for gene expression study (Rodrigues et al. 2003; Silveira et al. 2012), as apomictic and sexual plants are described within the same species, as in B. brizantha (Araujo et al. 2000). The embryo sacs of sexual and apomictic plants of Brachiaria are described, 
respectively, as being of the Polygonum type and Panicum type (Lutts et al. 1994; Dusi and Willemse 1999; Araujo et al. 2000). The Panicum-type embryo sac contains four cells: the egg cell, the central cell with one nucleus, and two synergids (Dusi and Willemse 1999; Araujo et al. 2000). The polar nucleus must be fertilized for endosperm formation (Alves et al. 2001). The development of anthers seems to be identical in sexual and apomictic plants of Brachiaria (Lutts et al. 1994; Dusi and Willemse 1999).

Generally, the molecular bases of reproduction are still not fully elucidated (Armenta-Medina et al. 2011). Gametophytes formation and the main reproductive events occur inside the ovaries and anthers; therefore, there is a great interest in identifying genes expressed in these organs. The isolation of the upstream sequences of these genes may help in the identification of the regulatory elements associated with reproduction and provide biotechnological tools for the breeding program of Brachiaria.

In this work, we characterize three cDNA isolated from ovaries of $B$. brizantha; clones 09 (CL09), 10 (CL10), and 21 (CL21) which showed strong expression in B. brizantha ovaries (Rodrigues et al. 2003), with the aim to identify promoter sequences which can be further used in the construction of vectors for the expression of transgenes in these structures. By in silico analysis of the complete ORF (open reading frame) of CL09, CL10, and CL21, it is shown that they code for ribosomal proteins and were named BbrizRPS8, BbrizRPS15a, and BbrizRPL41, respectively. Ribosomal proteins are known to be involved with synthesis and processing of proteins and play a role in balancing the synthesis of RNA and as structural components of the ribosome (Wool 1996). Recently, it has been suggested that genes coding for ribosomal proteins should not be considered only as constitutive genes because many of them are involved with extraribosomal functions (Mclntosh and Boham-Smith 2006; Warner and McIntosh 2009). Mutations in genes encoding ribosomal proteins suggest that the ribosome has a regulatory role in the development of plants and animals (Byrne 2009). Analysis of transcript abundance of a family of genes coding for ribosomal proteins in Arabidopsis thaliana has shown their high expression in reproductive tissues (Hulm et al. 2005; Shi and Yang 2011). In a transcriptome analysis of reproductive tissues of Brassica napus, microspores and ovules showed a higher fraction of genes coding for ribosomal proteins than pollen (Whittle et al. 2009). Together, these data show that ribosomal genes are developmentally regulated and have putative roles in reproductive development.

To investigate the association of BbrizRPS8, BbrizRPS15a, and BbrizRPL41, with development of ovaries and anthers, expression analyses were performed. We showed that under our experimental conditions, their activity is stronger in the early stages of anther development. In contrast, the expression in the ovaries is detected in all tested stages, from the early stages of development until maturity, before anthesis, except for BbrizS15a which is detected only in synergids of apomictic plants. The expression of the three genes encoding for ribosomal proteins of $B$. brizantha, BbrizRPS8, BbrizRPS15a, and BbrizRPL41 in development of ovaries and anthers is discussed.

\section{Material and methods}

Plant material

Two accessions of B. brizantha (Syn. Urochloa brizantha) from Embrapa's germplasm collection, cultivated in the field at Embrapa Genetic Resources and Biotechnology, Brasília, Federal District, Brazil, were used in this work: BRA002747, a diploid $(2 n=2 x=18)$ sexual, and BRA 000591 a tetraploid $(2 n=4 x=36)$ facultative apomictic named B. brizantha (A. Rich) Stapf cv. Marandu.

Ovaries and anthers of both accessions were dissected from flowers of different plants before anthesis, at different stages of development, under a Zeiss Stemi SV11 stereomicroscope. The stages of development were inferred by pistil morphology (Araujo et al. 2000; Rodrigues et al. 2003); stages I and II are related to megasporogenesis and stages III and IV to megagametogenesis. Young leaves were excised from plants grown in the field, and of root portions taken near the meristematic region were excised from plants cultivated in the greenhouse.

\section{Sequences analyses}

Analyses of the sequences from CL09 and CL10 were carried out using the program BLASTx against the database non-redundant (nr) protein sequences from NCBI and from CL21 using BLASTn against the database nr NCBI nucleotides (www.ncbi.nlm.gov/BLAST) (Altschul et al. 1997).

The plant cis-acting regulatory DNA elements (PLACE) database (http://www.dna.affrc.go.jp/PLACE/) was used for search the regulatory motifs in the promoter region of the sequences.

5' Rapid amplification of cDNA ends and promoter isolation

5' Rapid amplification of cDNA ends (RACE) was performed to isolate the full-length cDNA of clones 09 and 10 with the Marathon ${ }^{T M}$ cDNA Amplification Kit. A Marathon $^{\mathrm{TM}}$ cDNA library from ovaries, in megagametogenesis (stage IV) of B. brizantha was performed according to the manufacturer's protocol. The specific oligonucleotides for each of the clones are shown in Table 1. RACE09 1 and RACE10_1 were designed for the first 5' RACE reactions. Additional (nested) oligonucleotides (RACE09_2 and 
Table 1 Oligonucleotides designed for 5' RACE and Genome walking for clones 09,10 and 21 in sexual and apomictic $B$. brizantha

\begin{tabular}{ll}
\hline Name & Oligonucleotides sequences \\
\hline RACE09_1 & 5' CCTTCTTCCTCTGGAGCTTCTTCA 3' \\
RACE09_2 & 5' GTCGAGCTTCCTCTGGACATGGTT 3' \\
RACE10_1 & 5' CAGGCAAGTTTGACAAGGGCCAATAC 3' \\
RACE10_2 & 5' GGCTCAAGATCCCTCAAGGTGCAT 3' \\
GW09_1 & 5' CACGGACCCTCCTCACAGTCTTGTTGC 3' \\
GW09_2 & 5' ATACTTCCGCTTCTTCCTCCAGGCCTT 3' \\
GW10_1 & 5' AGAGGTTGTCAGGACAATGTAGCCAAA 3' \\
GW10_2 & 5' CCCGATGGTCATCAACATACTCAAACT 3' \\
GW10_3 & 5' TACATGGCTTATACATAGGCGCTGAGG 3' \\
GW10_4 & 5' ACAACCACACAAAAGCACCTACACAAT 3' \\
GW21_1 & 5' TTACTTAGATCTCTGCCTCATCTTTCG 3' \\
GW21_2 & 5' CGCTTCTTCTTCCACTTGGCCCTCATG 3' \\
\hline
\end{tabular}

RACE10_2) were used for the second 5' RACE reactions. The PCR cycle condition was: $94^{\circ} \mathrm{C}, 1 \mathrm{~min} ; 4$ cycles of $94^{\circ}$ C, $30 \mathrm{~s} ; 72^{\circ} \mathrm{C}, 4 \mathrm{~min} ; 4$ cycles of $94{ }^{\circ} \mathrm{C}, 30 \mathrm{~s} ; 70{ }^{\circ} \mathrm{C}, 4 \mathrm{~min}$; 34 cycles of $94^{\circ} \mathrm{C}, 20 \mathrm{~s} ; 68^{\circ} \mathrm{C}$, in Thermocycler Veriti ${ }^{\mathrm{TM}} 96$ well (Applied Biosystems).

The genomic DNA sequences $5^{\prime}$ adjacent to ATG of CL09, CL10, and CL21 were obtained according to GenomeWalker ${ }^{\mathrm{TM}}$ Universal Kit User Manual, Clontech. The genome walking libraries were constructed with genomic DNA from leaves of sexual and apomictic plants. DNA was digested with restriction enzymes Dra I, Eco RV, $P v u$ II, and Stu I and libraries were constructed according to the Genome Walker protocol. Two PCR reactions were performed with: $94{ }^{\circ} \mathrm{C}, 5 \mathrm{~min} ; 5$ cycles of $94{ }^{\circ} \mathrm{C}, 30 \mathrm{~s} ; 68{ }^{\circ} \mathrm{C}$, $3 \mathrm{~min} ; 30$ cycles of $94{ }^{\circ} \mathrm{C}, 30 \mathrm{~s} ; 68^{\circ} \mathrm{C}, 30 \mathrm{~s} ; 68^{\circ} \mathrm{C}, 3 \mathrm{~min}$, in Thermocycler Veriti ${ }^{\mathrm{TM}} 96$ well (Applied Biosystems).

Specific oligonucleotides for RACE and genome walking (Table 1) were designed in the antisense direction using Primer 3.0 program, following the information provided by manufacturer's protocol.

The PCR products were cloned into pGEM T-Easy vector System I (Promega) and competent Escherichia coli X11 Blue strain was transformed. Plasmid DNA-containing insert was purified (Sambrook and Russel 2001) and sequenced. Analysis of the sequences generated in the ABI3700 (Applied Biosystems) sequencer was done using electropherogram quality analysis program, on the site http://adenina.biomol.unb.br/phph (Togawa and Brigido 2003).

\section{Real-time PCR}

For real-time PCR (RT-qPCR) reaction, RNA was extracted from ovaries and anthers separately at the four stages of pistil development before anthesis (I, I, III, and IV) (Araujo et al. 2000). A sample containing equal amounts of RNA $(0.5 \mu \mathrm{g})$ from each stage of development was prepared for ovaries and anthers. RNA was extracted from ovaries and anthers using TRIzol ${ }^{\circledR}$ Reagent with a modified method from the manufacturer's instructions (Silveira et al. 2009). RNA was extracted from leaves and roots using $\mathrm{LiCl}$ according to Sambrook and Russel (2001). RNA was treated with DNAse I (Invitrogen ${ }^{\mathrm{TM}}$ ) and quantified using NanoDrop ND-1000 Spectrophotometer. cDNAs were synthesized from $2.0 \mu \mathrm{g}$ of total RNA and Oligo-dT primer using SuperScript ${ }^{\circledR}$ II Reverse Transcriptase (RT). Oligonucleotides (Table 2) were designed using Primer 3.0 program (melting temperature between 59 and $60^{\circ} \mathrm{C}$, primer lengths 19-21 bp and amplicon length between 100 and 200 bp). As reference gene, BbrizUBCE (ubiquitin-conjugating enzyme), described as the best reference gene for analyses in B. brizantha, was used (Silveira et al. 2009). Reactions were done in $20 \mu \mathrm{L}$ containing $5 \mu \mathrm{L}$ of cDNA (1:100), $0.2 \mathrm{M}$ of each primer and $10-\mu \mathrm{L}$ mix of Syber Green Rox Plus $\left(\mathrm{LGCBio}^{\mathrm{TM}}\right)$. PCR reactions were performed in Mastercycler ep realplex (Eppendorf ${ }^{\mathrm{TM}}$ ) using the cycling parameters: $95^{\circ} \mathrm{C}, 15 \mathrm{~min} ; 40$ cycles of $95^{\circ} \mathrm{C}$, $15 \mathrm{~s} ; 60^{\circ} \mathrm{C}, 15 \mathrm{~s} ; 95^{\circ} \mathrm{C}, 20 \mathrm{~min}$. The dissociation curve was obtained by heating the amplicon from 60 to $95{ }^{\circ} \mathrm{C}$ and reading for $20 \mathrm{~min}$. Three biological replicates were performed for each sample and three technical replicates were made for each biological replicate. The Microsoft Excel file (Microsoft, Redmond, WA) of raw expression Ct values was analyzed in Q-Gene software (Simon 2003). The primer efficiency was analyzed using a sample containing equal amounts of RNA $(0.5 \mu \mathrm{g})$ from each stage of development from ovaries and anthers using a pool of cDNAs. The reactions were performed in dilutions of 1:10, 1:20 and $1: 40$. Reactions were done in triplicate for each primer of specific genes and the Bbriz $\mathrm{UBCE}$, reference gene for analyses in B. brizantha (Silveira et al. 2009).
Table 2 Oligonucleotides designed for RT-qPCR analyses of BbrizRPS8, BbrizRPS15a, and BbrizRPL41 in sexual and apomictic $B$. brizantha

\begin{tabular}{ll}
\hline Clone & Oligonucleotides pair sequences \\
\hline BbrizRPS8 & 5' CCTGCTGCTAAGAAGGATGC 3'/5' CACTGCCAAATTGCTCTTCA 3' \\
BbrizRPS15a & 5' CAAGTTCCTCATCGTCATGC 3'/5' GGGCTGATCACTCCACACTT 3' \\
BbrizRPL41 & 5' AAGAAGAAGCGCATGAGGAG 3'/5' GCATACAAAGCTTGCCATCA 3' \\
\hline
\end{tabular}


In situ hybridization

In situ hybridization was performed in semithin sections of $3.5 \mu \mathrm{m}$ of ovaries and anthers during sporogenesis and gametogenesis. Tissue preparation, hybridization, and posthybridization reactions were performed according to Dusi (2001). The RNA probe was synthesized using the Digoxigenin RNA labeling kit (Roche) following the manufacturer's instructions. PCR fragments of 200-450 bp were cloned into pGEM $^{\circledR-} \mathrm{T}$ Easy Vector Systems $\left(\right.$ Invitrogen ${ }^{\mathrm{TM}}$ ) and linearized by digestion with $\mathrm{Sal} \mathrm{I}$ and Nco I (Invitrogen ${ }^{\mathrm{TM}}$ ) to generate $5^{\prime}$ protruding ends. T7 and SP6 polymerases were used to synthesize sense and antisense probes, respectively. Sections were hybridized with $60 \mathrm{ng}$ of the DIG-labeled RNA probe, diluted in $100 \mu \mathrm{L}$ of hybridization buffer, overnight at $42{ }^{\circ} \mathrm{C}$. After antibody reaction, detection, and washings, the sections were mounted in Permount SP15-500 (Fisher Scientific) and observed with a ZeissAxiophot light microscope. Some sections were stained with acridine orange and examined under UV light to verify RNA integrity.

\section{Results}

The three cDNA sequences showed similarity with genes coding to ribosomal proteins

The complete ORFs of CL09 (666 bp) and CL10 (657 bp) were recovered by 5' RACE technique. The full-length CL21 sequence ( $75 \mathrm{bp}$ ) had been previously obtained (Rodrigues et al. 2003). Genome sequences 5' upstream of the ATG (initiation codon) were isolated by genome walking with 1,064 ,
705, and 1,770 bp for CL09, CL10 and CL21, respectively. Introns were identified near to ATG with $120 \mathrm{bp}$ for CL09 and $77 \mathrm{bp}$ for CL10. The three sequences showed similarity to ribosomal proteins in available databases (www.ncbi.nlm.gov/BLAST) (Table 3). Table 3 shows the analyses of derived amino acid sequences of the three clones. CL09 is similar to ribosomal protein S8, CL10 to ribosomal protein S15A and CL21 to L41 and were named BbrizRPS8, BbrizRPS15a, and BbrizRPL41. The three clones were also found in the EST library of B. brizantha ovaries (Silveira et al. 2012).

The promoter regions of the sequences were analyzed and motifs related to pollen specific expression (POLLEN1LELAT52), elements root specific (ROOTMOTIFTAPOX1) and elements related to response to auxin, were found in the three clones. The ASF1 binding site, involved in transcriptional activation of several genes by auxin, is present in the BbrizRPS8 promoter region and in the intron sequence from BbrizSRP15a. The auxinresponsive element, a binding site for auxin-response factors, is present in the BbrizRPS15a promoter region and in the BbrizRPL41 promoter region (Fig. 1).

BbrizRPS8, BbrizRPS15a, and BbrizRPL41

are preferentially expressed in reproductive organs and roots

In order to characterize sequences with preferential expression in reproductive organs, RT-qPCR was performed to evaluate the difference of expression of ribosomal genes between reproductive organs (ovaries and anthers) and vegetative organs (leaves and roots). The amplification efficiency for each primers pairs was analyzed. For BbrizRPS8 the efficiency was $108 \%$, for BbrizRPS15a was $107 \%$, for BbrizRPL41 was $109 \%$, and BbrizUBCE was $105 \%$.

Table 3 Analysis of the sequences of clones 09, 10 and 21 using the program BLASTX against the database $\mathrm{nr}$ (non-redundant) protein sequences from NCBI and clone 21 using BLASTN against the

database nr (non-redundant) NCBI nucleotides (www.ncbi . nlm.gov/ BLAST) (Altschul et al. 1997)

\begin{tabular}{|c|c|c|c|c|}
\hline Clone & GenBank ID & Sequences & e value & Similarity, $\%$ \\
\hline \multirow[t]{4}{*}{09} & XP_002452585.1 & $\begin{array}{l}\text { Sorghum bicolor-hypothetical protein SORBIDRAFT_04g028530 } \\
\text { - similar to protein } 40 \mathrm{~S} \text { ribossomal S8 }\end{array}$ & $7 e-95$ & 95 \\
\hline & NP_001105391.1 & Zea mays $-40 \mathrm{~S}$ ribosomal protein $\mathrm{S} 8$ & $1 \mathrm{e}-94$ & 94 \\
\hline & BAA07207.1 & Oryza sativa-ribosomal protein $\mathrm{S} 8$ & $6 e-94$ & 90 \\
\hline & NP_197529.1 & Arabidopsis thaliana-40 S ribosomal protein S8-1 & $5 e-86$ & 79 \\
\hline \multirow[t]{4}{*}{10} & NP_001146975.1 & Zea mays-40 S ribosomal protein $\mathrm{S} 15 \mathrm{a}$ & $2 e-67$ & 99 \\
\hline & NP_172256.1 & Arabidopsis thaliana $-40 \mathrm{~S}$ ribosomal protein $\mathrm{S} 15 \mathrm{a}-1$ & $3 e-67$ & 97 \\
\hline & Q00332.3 & Brassica napus-40 S ribosomal protein $\mathrm{S} 15 \mathrm{a}$ & $8 \mathrm{e}-67$ & 96 \\
\hline & NP_001046846.1 & Oryza sativa-40 S ribosomal protein $\mathrm{S} 15 \mathrm{a}$ & $7 e-66$ & 96 \\
\hline \multirow[t]{4}{*}{21} & AY109380.1 & Zea mays-CL2281_1 mRNA sequence & $9 \mathrm{e}-30$ & 96 \\
\hline & D50573.1 & Oryza sativa - mRNA similar to ribosomal protein L41 & $5 e-29$ & 96 \\
\hline & AJ001160.1 & Hordeum vulgare - ribosomal protein L41 & $1 \mathrm{e}-19$ & 92 \\
\hline & U26255.1 & Nicotiana tabacum - ribosomal protein L41 & $5 e-22$ & 93 \\
\hline
\end{tabular}




BbrizRPS8
\begin{tabular}{|l|l:l|l|l|l|l|l|}
\hline 1064 & ATG $\rightarrow$ & \\
\hline
\end{tabular}

BbrizRPS15a

\begin{tabular}{|l|l:l|l|l|l|}
\hline 705 & ATG $\rightarrow$ & & \\
\hline
\end{tabular}

\section{BbrizRPL41}

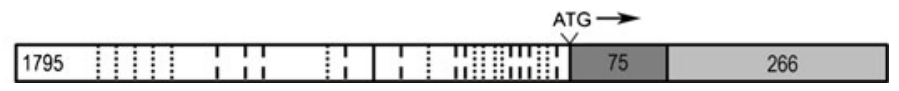

Fig. 1 Schematic representation of BbrizRPS8, BbrizRPS15a and BbrizRPL41 genes showing ORF (open read frame) and $5^{\prime}$ upstream sequence of the ATG start codon. $5^{\prime}$ upstream sequences are shown in white. Different black bars indicate putative regulatory elements: solid bar elements related to response to auxin, dotted bar elements of

The RT-qPCR results showed that all three clones are highly expressed in roots, suggesting activity in cells undergoing mitosis. Higher expression levels were also observed in reproductive organs (ovaries and anthers) when compared to leaves (Fig. 2). In ovaries, the level of expression in sexual and apomictic plants was similar for the three clones. In anthers, all clones showed slightly higher expression in apomictic than in sexual plants. Aiming to investigate the expression of the three clones during development of reproductive organs, in situ hybridization analyses were carried out in ovaries and anthers of sexual and apomictic plants of $B$. brizantha.

Transcripts of BbrizRPS8 and BbrizRPL41 were similarly localized during development of ovaries in apomictic and sexual plants

Due to high expression of BbrizRPS8, BbrizRPS15a, and BbrizRPL41 in reproductive organs, in situ hybridization was performed to localize the transcripts inside the ovaries and anthers.

The sections stained with acridine orange showed the orange colour that indicates RNA presence in nucleolus and cytoplasm of the cells (Fig. 3a). In situ hybridization with antisense probe of BbrizRPS 8 revealed expression in ovaries of both sexual and apomictic plants (Fig. 3b-f). During megasporogenesis (Fig. 3b-d), in apomicts, a strong hybridization pollen specific expression and dash bar root specific elements. Exons are shown in gray. Introns are shown in black and 3' UTR (untranslated region) are shown in light gray. Numbers inside the boxes indicate length of segments in base pairs. An arrowhead (" $V$ ") indicate the transcription start site

signal was observed in the meiocyte and a very weak signal in the nucellus and surrounding tissues (Fig. 3b). In sexual plants, the expression was widespread in the ovary with stronger signal in the archesporial cell (Fig. 3c) and dyad (Fig. 3d). During megagametogenesis (Fig. 3e-f), a strong hybridization signal was observed in the integuments, nucellus and embryo sacs of apomicts (Fig. 3e) and in the integuments, nucellus cells and antipodal cells in sexuals (Fig. 3f). In anthers of both apomictic and sexual plants, transcripts were located at the beginning of development with a strong signal in the pollen mother cell, tapetum and surrounding layers (Fig. 3g). In a little more advanced stage, signal was detected only in the meiocyte (Fig. 3h). In mature anthers, no signal was observed in pollen grains (Fig. 3i). Sense probes (negative control) hybridization was not detected in ovaries and anthers of both apomictic and sexual plants of $B$. brizantha in equivalent stages of development (Fig. $3 \mathrm{j}-1$ ).

For BbrizRPL41, in situ hybridization with antisense probe revealed expression in ovaries of both sexual and apomictic plants (Fig. 4a-f). During megasporogenesis, in apomictic plants, transcripts were markedly observed in the archespore cell (Fig. 4a) and the meiocyte but also in the surrounded nucellus and integuments (Fig. 4b). In the sexual plant, a signal was observed in young ovaries, especially in the archesporial cell (Fig. 4c) and dyad (Fig. 4d). During megagametogenesis, in apomicts, a signal was observed in
BbrizRPS8
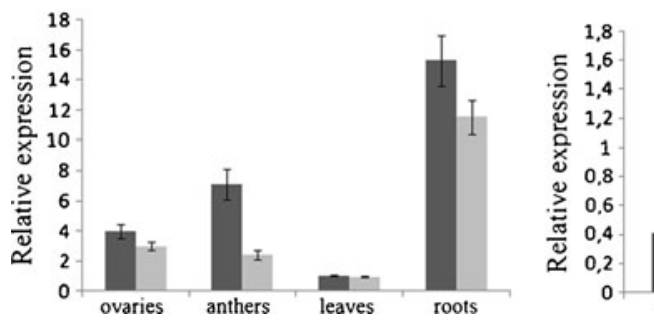

BbrizRPS15a

Fig. 2 Relative expression of BbrizRPS8, BbrizRPS15a, and BbrizRPL41 in ovaries, anthers, leaves, and roots of plants of apomictic (black columns) and sexual (gray columns) B. brizantha. Gene
BbrizRPL41

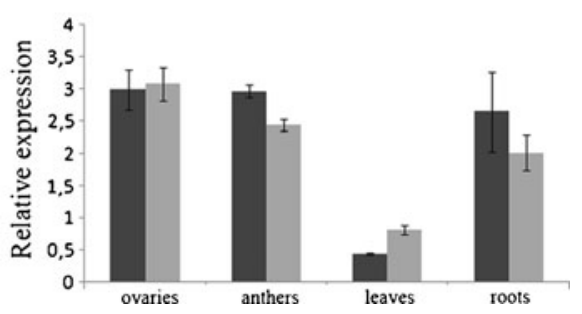

expression was normalized with BbrizUBCE of B. brizantha (Silveira et al. 2009). Results represent the mean of three technical replicates of each sample and bar shows the standard error of the mean 

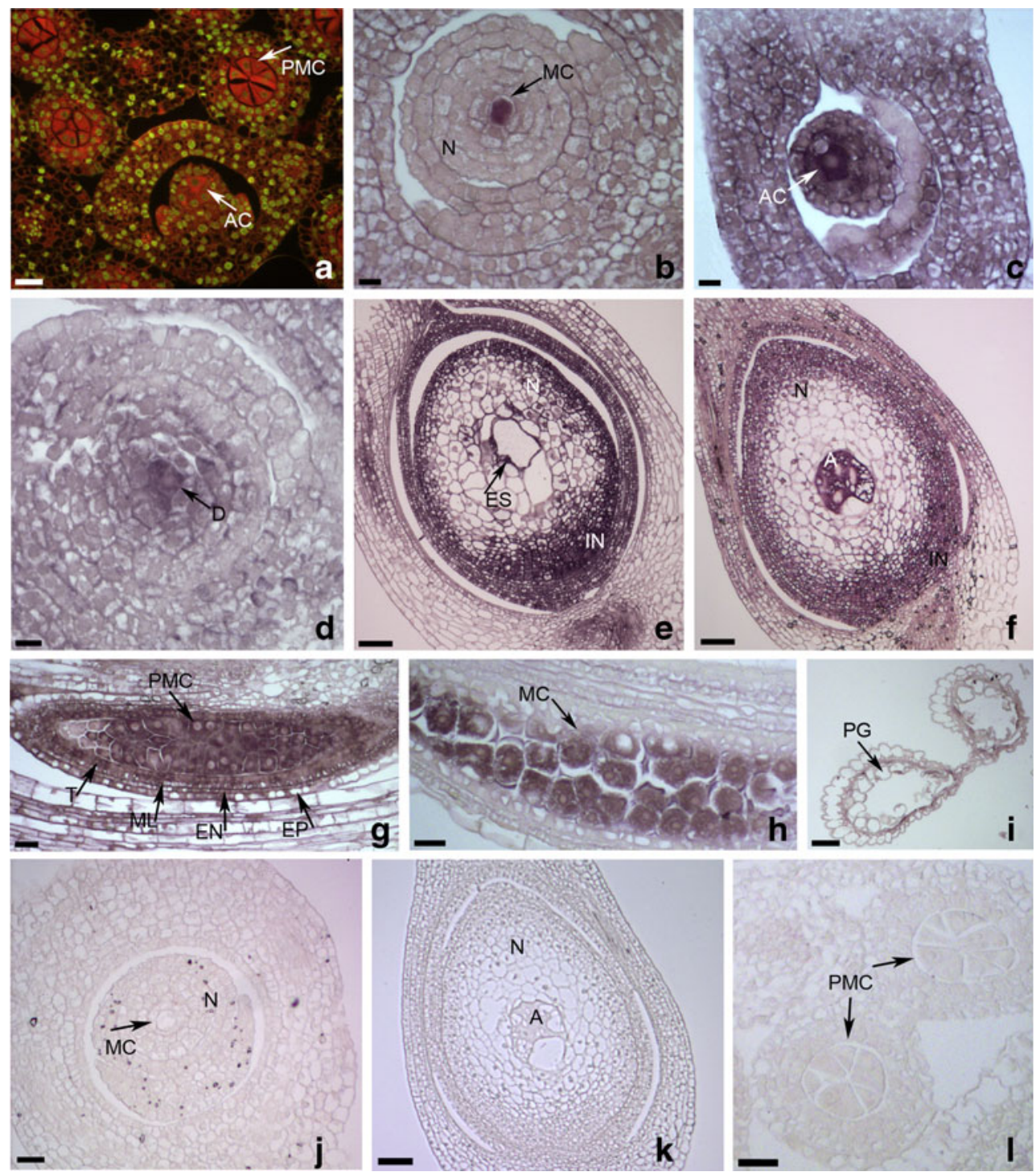

Fig. 3 Localization of BbrizRPS 8 expression by in situ hybridization in semithin sections of ovaries and anthers of apomictic and sexual $B$. brizantha. Ovaries $(\mathrm{a}-\mathrm{f}, \mathrm{j}, \mathrm{k})$ and anthers $(\mathrm{g}-\mathrm{i}, \mathrm{l})$ hybridized with antisense $(b-i)$ and sense probe $(j-1)$ showing: a RNA preservation (orange) in control after acridine orange staining in the anthers with pollen mother cell and ovary with archespore cell; b-d at megasporogenesis, strong signal in the meiocyte of apomicts (b) and in the ovary with archespore cell (c), and dyad (d) of sexuals; e, f at megagametogenesis, strong hybridization signal in the embryo sac, nucellus and integuments of apomicts (e) and in the embryo sac, nucellus, integuments and antipodal cells of sexuals (f); $\mathbf{g}, \mathbf{h}$ at microsporogenesis,

nucellus cells and integuments including the egg apparatus (Fig. 4e). In sexuals, a strong signal was observed in the mature embryo sac: integuments, nucellus cell, antipodal cells and egg apparatus (Fig. 4f). In anthers of both apomictic and sexual plants, a hybridization signal was shown in the pollen mother cell, tapetum, and surrounding layers (Fig. 4g) and uninucleate microspores (Fig. 4h). No signal was observed in pollen grain (Fig. 4i). Sense probes (negative control) hybridization was not detected in ovaries and strong signal in: the pollen mother cell, tapetum, middle layer, endothecium, and epidermis of sexuals ( $\mathbf{g})$ and the meiocyte of apomicts (h); i mature anther with no signal in pollen grains of apomicts; $\mathbf{j}$ $\mathbf{l}$ absence of signal in sense controls in apomicts at megasporogenesis (j); in sexuals at megagametogenesis (k) and in apomicts at microsporogenesis (l). $A$ : antipodal cells; $A C$ : archespore cell; $D$ : dyad; $E N$ : endothecium; $E P$ : epidermis; $E S$ : embryo sac; $I N$ : integuments; $M C$ : meiocyte; $M L$ : middle layer; $N$ : nucellus; $P G$ : pollen grain; $P M C$ : pollen mother cell; $T$ : tapetum. scale bars $\mathbf{b}, \mathbf{c}, \mathbf{d}=10 \mu \mathrm{m} ; \mathbf{a}, \mathbf{g}, \mathbf{h}, \mathbf{j}$, $\mathbf{l}=20 \mu \mathrm{m} ; \mathbf{e}, \mathbf{f}, \mathbf{i}, \mathbf{k}=50 \mu \mathrm{m}$

anthers of both apomictic and sexual plants of $B$. brizantha in equivalent stages of development (Fig. $4 \mathrm{j}-1$ ).

BbrizRPS15a expression was observed only in synergids of apomictic plants

No signal of in situ hybridization was detected with the sense probe (Fig. 5a). Under our experimental conditions, in situ hybridization with antisense probe of BbrizRPS15a 


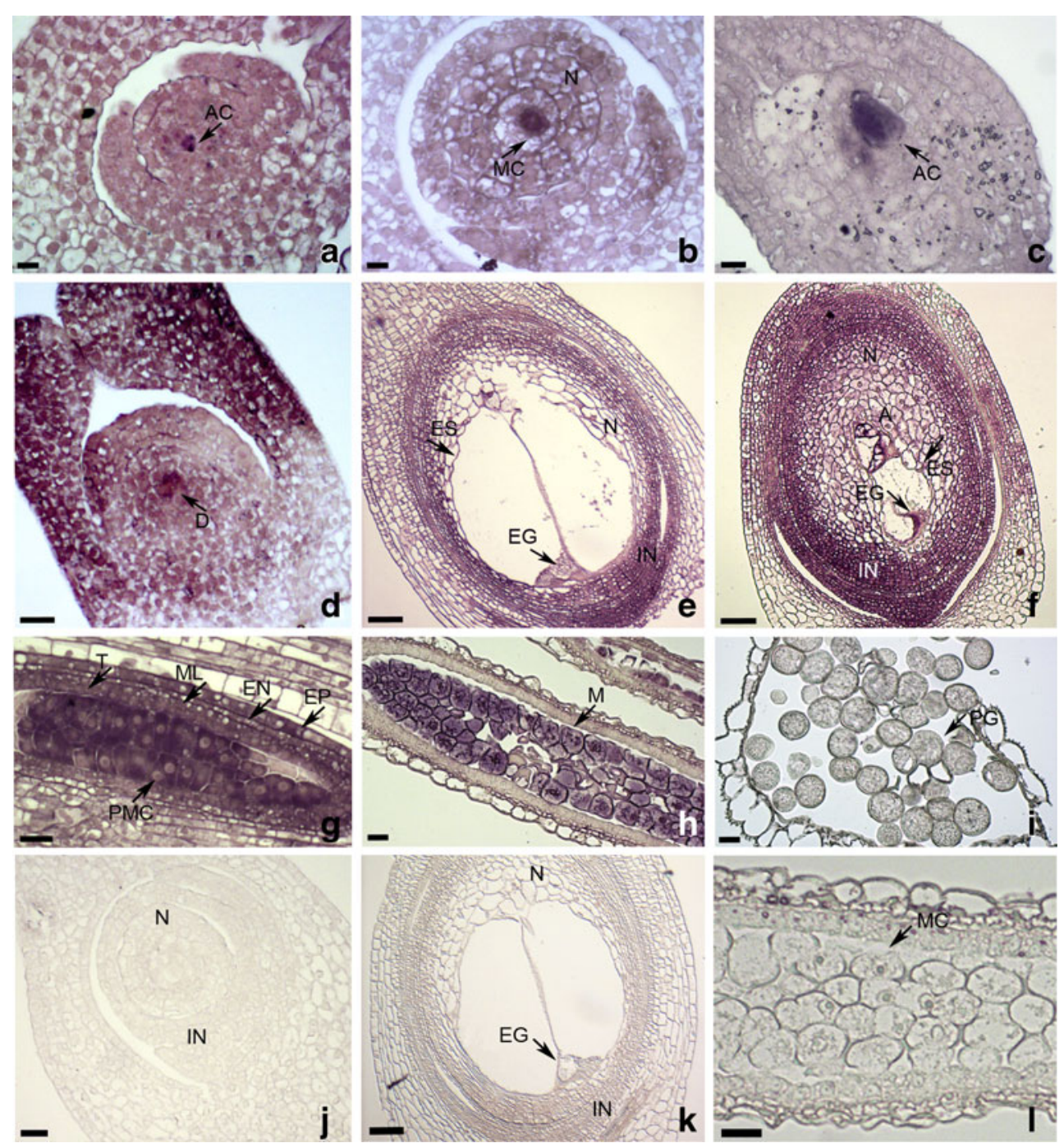

Fig. 4 Localization of BbrizRPL41 expression by in situ hybridization in semithin sections of ovaries and anthers of $B$. brizantha. Ovaries (a$\mathbf{f}, \mathbf{j}, \mathbf{k})$ and anthers $(\mathbf{g}-\mathbf{i}, \mathbf{l})$ hybridized with anti-sense (a-i) and sense (j-l) probes showing: a-d at megasporogenesis, hybridization widespread in ovaries with stronger signal in the archespore cell (a) and in the meiocyte (b) of apomicts and in the archespore cell (c), and dyad (d) of sexuals; $\mathbf{e}, \mathbf{f}$ at megagametogenesis, hybridization signal in the nucellus cells and integuments, with weak signal in the egg cell of apomicts (e) nucellus, integuments, and in the embryo sac in antipodal cells and egg apparatus of sexuals (f); $\mathbf{g}-\mathbf{i}$ at microsporogenesis, strong

revealed a very specific pattern of expression in ovaries (Fig. 5b-e). In apomicts, a weak hybridization signal was observed in the nucellus of ovules containing the megaspore mother cell (Fig. 5b) and coenocytes. Following development, no signal was detected up to the mature embryo sac stage, when a strong hybridization signal was observed at the base of the synergids, near the filiform apparatus (Fig. 5c). The same pattern of hybridization was observed in mature embryo sacs, ready to be fertilized. In ovaries of sexual plants, no signal was detected during megasporogenesis (Fig. 5d) or megagametogenesis (Fig. 5e) including the signal in the pollen mother cell, tapetum, middle layer, endothecium and epidermis (g) and uninucleate microspores (h), with no signal in pollen grains (i) of sexuals; $\mathbf{j}-\mathbf{l}$ absence of signal in sense controls in apomicts at megasporogenesis (j) and megagametogenesis (k) and in sexuals microsporogenesis (l). $A$ : antipodal cells; $A C$ : archespore cell; $D$ : dyad; $E G$ : egg cell; $E N$ : endothecium; $E P$ : epidermis; $E S$ : embryo sac; $I N$ : integuments; $M C$ : meiocyte; $M$ : microspores; $M L$ : middle layer; $N$ : nucellus; $P M C$ : pollen mother cell; $P G$ : pollen grain; $T$ : tapetum. scale bars $\mathbf{a}, \mathbf{c}, \mathbf{d}=10 \mu \mathrm{m} ; \mathbf{g}, \mathbf{h}, \mathbf{j}=20 \mu \mathrm{m} ; \mathbf{e}, \mathbf{f}, \mathbf{i}, \mathbf{k}=50 \mu \mathrm{m}$

egg apparatus (Fig. 5f). The pattern of expression in anthers was identical to that of BbrizRPS8 and BbrizRPL41.

\section{Discussion}

The three genes of ribosomal proteins identified in this work seem to be conserved in plants, with high similarity levels detected among other monocots. CL09 is similar to the ribosomal protein $\mathrm{S} 8$, therefore renamed BbrizRPS8. The S8 coding sequence was well characterized in rice 


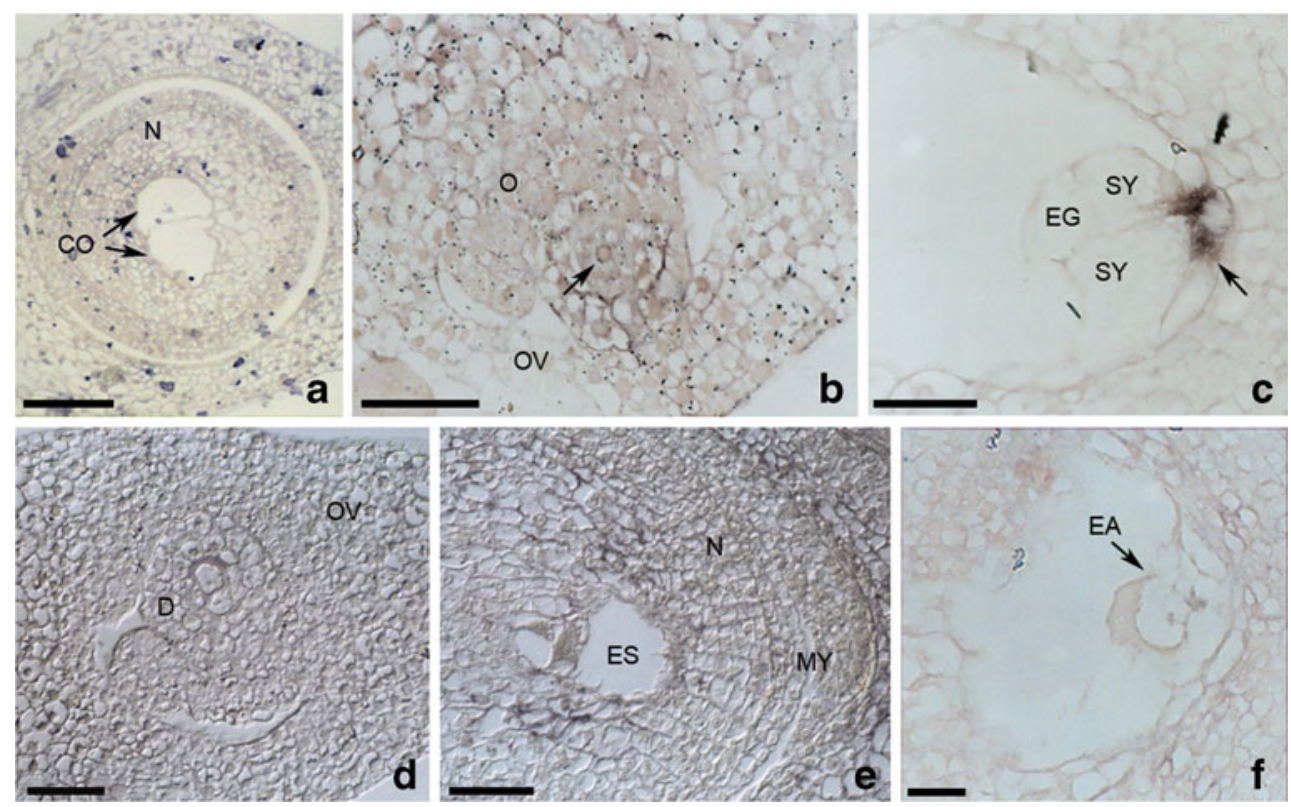

Fig. 5 Localization of BbrizRPS15a expression by in situ hybridization in semithin sections of ovaries of apomictic and sexual B. brizantha. Ovaries hybridized with sense (a) and anti-sense probes (b-f) showing: a, b at megasporogenesis, absence of signal in the control (a) and weak signal in the ovary and megaspore mother cell (arrow) in the ovule (b) of apomicts; c mature embryo sac with hybridization

(Nakamura et al. 1995) and it was suggested that S8 may play an important role in specific regulation during protein synthesis in eukaryotic cells. CL10, with higher similarity with proteins from the ribosomal protein family S15a from maize, and from $A$. thaliana (Hulm et al. 2005), especially with the isoform RPS15aF was renamed BbrizRPS15a. CL21 is similar to ribosomal proteins L41, which are considered to be the smallest and most basic eukaryotic proteins, with 25 aminoacids, 17 of them being Arg or Lys (Yu and Warner 2001) and was renamed BbrizRPL41. In Hordeum vulgare, S8 and L41 genes were found to be more expressed in the floral structures, lemma, and palea, than in the flag leaf (Abebe et al. 2004).

Regulatory motifs related to auxin identified in the promoter regions of the three ribosomal genes suggest a possible association of their high expression in ovaries, anthers, and roots, with high mitotic activity, typical of these organs. Auxin plays an important role in the induction of cell division (Perrot-Rechenmann 2010) and the possibility of regulation of these genes by auxin should be further investigated.

All three genes encoding ribosomal proteins analyzed (BbrizRPS8, BbrizRPS15a, and BbrizRPL41) showed reduced expression in leaves. Although high expression was observed in anther tissue, we did not detect transcripts in mature pollen by in situ hybridization, suggesting that the expression observed in anther tissue is mainly due to transcription during early events of anther development. Consistent with this, a large-scale transcript profiling study strictly in the base (arrow) of the synergids of apomicts; d, e dyad (d) and young embryo sac (e) in sexuals without hybridization signal; $\mathbf{f}$ egg apparatus of sexuals without hybridization signal. $C O$ : coenocytes; $D$ : dyad; $E A$ : egg apparatus; $E G$ : egg cell; $E S$ : embryo sac; $M Y$ : micropylar pole; $N$ : nucellus; $O$ : ovule; $O V$ : ovary; $S Y$ : synergid. scale bars $\mathbf{a}=20 \mu \mathrm{m} ; \mathbf{b}, \mathbf{c}, \mathbf{d}, \mathbf{e}=10 \mu \mathrm{m} ; \mathbf{f}=5 \mu \mathrm{m}$

in B. napus showed low activity of genes encoding ribosomal proteins in leaves and mature pollen, suggesting that a reduced level of transcripts is sufficient to support growth and development of these tissues, with high activity detected in developing microspores (Whittle and Krochko 2009).

The higher expression of BbrizRPS8, BbrizRPS15a, and BbrizRPL41 in reproductive organs compared to leaves is consistent with results obtained with other ribosomal proteins that are involved in plant and female gametophyte development (Hulm et al. 2005; Whittle and Krochko 2009; Shi et al. 2005; Skinner et al. 2001). In A. thaliana, it was observed that the ribosomal protein $\mathrm{S} 15 \mathrm{aF}$, similar to BbrizRPS15a, shows the highest transcript abundance in mitotically active tissues: buds followed by flowers, carpels and roots, with the lowest levels of transcript in leaves and bracts (Hulm et al. 2005).

In B. napus, the amount of transcripts of ribosomal proteins varies among tissues, with a very high fraction of the transcriptome occurring in highly differentiating and specialized cells, such as microspores and cells from embryo and ovules (Whittle and Krochko 2009). In B. brizantha, transcripts of BbrizRPS8 and BbrizRPL41 were localized in ovaries from the beginning of development up to maturity in apomictic and sexual plants. The transcripts were highly abundant in cells undergoing meiosis, meiocytes in ovaries and in anthers. Also, in growing ovule tissues such as nucellus, integuments and in antipodal cells, expression was detected for BbrizRPS8 and BbrizRPL41. The pattern 
of expression observed for these genes is consistent with sites of active protein synthesis. This finding does not exclude the possibility that these genes have an extraribosomal function related to gametophyte development. Recent studies showed that mutations in genes involved in ribosome biogenesis are crucial for embryo sac development in Arabidopsis, leading to an arrest of mitotic progression of the gametophytic cell cycle (Shi and Yang 2011; Shi et al. 2005). The Huellenlos gene from Arabidopsis that encode the mitochondrial ribosomal protein L14 is involved in the control of growth of the integument, embryo sac development and the prevention of cell death (Skinner et al. 2001; Schneitz et al. 1998). Nuclear fusion defective 1 encodes the mitochondrial ribosomal protein RPL21M in Arabidopsis, and the $n f d l$ female gametophytes have a defect in karyogamy during fertilization in egg cell and the central cell (Portereiko et al. 2006).

In anthers, location of BbrizRPS15a transcripts was similar to BbrizRPS8 and BbrizRPL41, with a strong signal in the meiocytes. In ovaries of sexual plants, although the expression of BbrizRPS15a was detected by RT-qPCR, we did not observe BbrizRPS15a transcripts by in situ hybridization, perhaps as a consequence of sensitivity under our experimental conditions. In contrast, BbrizRPS15a expression could be observed only in synergids of apomictic plants. Interestingly, BbrizAQP and BbrizMAPK were also shown to be differentially expressed in synergids of apomictic plants, when compared to sexual plants, pointing to differences in the transcription profile located at the bases of the synergid of apomicts (Alves et al. 2007). The identification of several ESTs that are expressed in synergids of apomictic plants suggests a putative role in autonomous development of the unreduced egg cell (Alves et al. 2007). Synergid cells are involved in the attraction and guidance of the pollen tube during fertilization (Van Went and Willemse 1984; Higashiyama 2002). In synergids, the abundance of calcium is closely related with pollen tube entrance in the embryo sac (Ge et al. 2007) and ribosomal proteins, including RPS8 and RPS15a, were identified as $\mathrm{Ca}_{2}^{+} /$calmodulinbinding proteins in a human proteome study (Shen et al. 2005). One can speculate on a putative association between $\mathrm{Ca}^{+}$metabolism and the specific synergid expression found for BbrizRPS15a, which is similar to RPS15aF. To our knowledge this function has not been investigated for ribosomal proteins in plants.

In this study, the expression of BbrizRPS8, BbrizRPS15a, and BbrizRPL41 was observed in mitotically active cells, in growing ovule tissues and roots, consistent with the expression of genes encoding ribosomal proteins in other plants (Hulm et al. 2005).

The preferential expression of BbrizRPS15a in synergids of apomictic plants may be related to autonomous development of the unreduced egg cell. The similar expression pattern of BbrizRPS8 and BbrizRPL41 suggest that these genes could be involved in general activities regulating growth and development of ovaries and anthers, irrespective of the mode of reproduction. The characterization of their upstream regulatory sequences will be of interest in order to identify the minimal promoter regions for ovary-specific expression of candidate genes related to the mode of reproduction of $B$. brizantha plants among the cDNA sequences already identified (Rodrigues et al. 2003; Silveira et al. 2012), as in ovaries the main morphological differences among sexual and apomictic plants occur.

Acknowledgments The authors gratefully acknowledge Larissa A. Guimarães and Andrea D. Koehler for technical help during RNA extraction and Flávia S. Ferreira for dissecting ovaries. This work is part of ALML's PhD thesis from Pós-Graduação em Biologia Molecular, UnB, Brazil, with a partial fellowship from CNPq and Embrapa. This work was partially supported by CNPq (490749/2008-9- VTCC) and Embrapa (02.05.1.02.00- VTCC).

Conflict of interest The authors declare that there is no conflict of interest in publishing the data shown at this manuscript.

\section{References}

Abebe T, Skadsen RW, Kaeppler HF (2004) Cloning and identification of highly expressed genes in barley lemma and palea. Crop Sci 44 (3):942-950

Altschul SF, Madden TL, Schaffer AA, Zhang J, Zhang Z, Miller W, Lipman DJ (1997) Gapped BLAST and PSI-BLAST: a new generation of protein database search programs. Nucl Acids Res 25(17):3389-3402. doi:10.1093/nar/25.17.3389

Alves ER, Carneiro VTC, Araujo A (2001) Direct evidence of pseudogamy in an apomictic Brachiaria brizantha (Poaceae). Sex Plant Reprod 14(4):207-212

Alves ER, Carneiro VTC, Dusi DMA (2007) In situ localization of three cDNA sequences associated with the later stages of aposporic embryo sac development of Brachiaria brizantha. Protoplasma 231(3):161-171

Araujo ACG, Mukhambetzhanov S, Pozzobon MT, Santana EF, Carneiro VTC (2000) Female gametophyte development in apomictic and sexual Brachiaria brizantha (Poaceae). Rév Cytol Biol Vég Bot T XXIII(1-2):13-28

Araújo SAC, Deminics BB, Campos PRSS (2008) Melhoramento genético de plantas forrageiras tropicais no Brasil. Arch Zootec 57(R):61-76

Armenta-Medina A, Demesa-Arévalo E, Vielle-Calzada J-P (2011) Epigenetic control of cell specification during female gametogenesis. Sex Plant Reprod 24(2):137-147

Byrne ME (2009) A role for the ribosome in development. Trends Plant Sci 14(9):512-519

CREMAQ P (2010) The miracle of the cerrado. Brazil has revolutionised its own farms. Can it do the same for others? The Economist. http:// www.economist.com/node/16886442/print?story_id=16886442

Dusi DMA (2001) Apomixis in Brachiaria decumbens Stapf. PhD thesis, University of Wageningen, Wageningen

Dusi DMA, Willemse MTM (1999) Apomixis in Brachiaria decumbens Stapf.: gametophytic development and reproductive calendar. Acta Biol Cracov Ser Bot 41:151-162 
Ge LL, Tian HQ, Russell SD (2007) Calcium function and distribution during fertilization in angiosperms. Am J Bot 94(6):1046-1060. doi:10.3732/ajb.94.6.1046

Higashiyama T (2002) The synergid cell: attractor and acceptor of the pollen tube for double fertilization. J Plant Res 115(2):0149-0160

Hulm JL, McIntosh KB, Bonham-Smith PC (2005) Variation in transcript abundance among the four members of the Arabidopsis thaliana RIBOSOMAL PROTEIN S15a gene family. Plant Sci 169(1):267-278

Lutts S, Ndikumana J, Louant BP (1994) Male and female sporogenesis and gametogenesis in apomitic Brachiaria brizantha, Brachiaria decumbens and F1 hybrids with sexual colchicine induced tetraploid Brachiaria ruziziensis. Euphytica 78:19-25

Mclntosh KB, Boham-Smith PC (2006) Ribosomal protein gene regulation: what about plants? Can J Bot 84:342-362

Miles JW, Maass BL, Valle CB (1996) Brachiaria: biology, agronomy and improvement, vol. 1, 1st edn. CIAT, Cali

Nakamura I, Kameya N, Aoki T, Tada T, Norita E, Kanzaki H, Uchimiya H (1995) Nucleotide sequence of a rice cDNA encoding a homolog of the eukaryotic ribosomal protein S8. Plant Physiol 107(4):1463-1464

Nogler GA (1984) Gametophytic apomixis. In: Johri BM (ed) Embriology of angiosperms. Springer, Berlin, pp 475-518

Perrot-Rechenmann C (2010) Cellular responses to auxin: division versus expansion. Cold Spring Harb Perspect Biol 2(5). doi:10.1101/cshperspect.a001446

Portereiko MF, Sandaklie-Nikolova L, Lloyd A, Dever CA, Otsuga D, Drews GN (2006) NUCLEAR FUSION DEFECTIVE1 encodes the Arabidopsis RPL21M protein and is required for karyogamy during female gametophyte development and fertilization. Plant Physiol 141(3):957-965. doi:10.1104/pp. 106.079319

Renvoize SA, Clayton WD, Kabuye CHS (1996) Morphology, taxonomy, and natural distribution of Brachiaria (Trin.) Griseb. In: Brachiaria: biology, agronomy and improvement, vol. 1, 1st edn. CIAT, Cali, Colombia, p 258

Rodrigues JCM, Cabral GB, Dusi DMA, Mello LV, Rigden D, Carneiro VTC (2003) Identification of differentially expressed cDNA sequences in ovaries of sexual and apomictic plants of Brachiaria brizantha. Plant Mol Biol 53:745-757

Sambrook J, Russel DW (2001) Molecular cloning: a laboratory manual, 3 edn. New York

Schneitz K, Baker SC, Gasser CS, Redweik A (1998) Pattern formation and growth during floral organogenesis: HUELLENLOS and AINTEGUMENTA are required for the formation of the proximal region of the ovule primordium in Arabidopsis thaliana. Development 125(14):2555-2563

Shen X, Valencia CA, Szostak JW, Dong B, Liu R (2005) Scanning the human proteome for calmodulin-binding proteins. PNAS 102 (17):5969-5974. doi:10.1073/pnas.0407928102
Shi D-Q, Yang W-C (2011) Ovule development in Arabidopsis: progress and challenge. Curr Opin Plant Biol 14(1):74-80

Shi D-Q, Liu J, Xiang Y-H, Ye D, Sundaresan V, Yang W-C (2005) SLOW WALKER1, essential for gametogenesis in Arabidopsis, encodes a WD40 protein involved in $18 \mathrm{~S}$ Ribosomal RNA Biogenesis. Plant Cell 17(8):2340-2354. doi:10.1105/ tpc. 105.033563

Silveira E, Alves-Ferreira M, Guimarães L, Silva F, Carneiro VTC (2009) Selection of reference genes for quantitative real-time PCR expression studies in the apomictic and sexual grass Brachiaria brizantha. BMC Plant Biol 9(1):84

Silveira E, Guimarães L, de Dusi DMA, Silva F, Martins N, do Carmo Costa M, Alves-Ferreira M, Carneiro VTC (2012) Expressed sequence-tag analysis of ovaries of Brachiaria brizantha reveals genes associated with the early steps of embryo sac differentiation of apomictic plants. Plant Cell Rep 31(2):403-416

Simon P (2003) Q-Gene: processing quantitative real-time RT-PCR data. Bioinformatics 19(11):1439-1440. doi:10.1093/bioinformatics/btg 157

Skinner DJ, Baker SC, Meister RJ, Broadhvest J, Schneitz K, Gasser CS (2001) The Arabidopsis HUELLENLOS gene, which is essential for normal ovule development, encodes a mitochondrial ribosomal protein. Plant Cell 13(12):2719-2730. doi:10.1105/ tpc. 010323

Togawa RC, Brigido MM (2003) PHPH: Web based tool for simple electropherogram quality analysis. In: IcoBiCoBi (ed) 1 st International Conference on Bioinformatics and Computational Biology, IcoBiCoBi, Ribeirão Preto

Valle CB, Bonato ALV, Pagliarini MS, Resende RMS, Jank L (2004) Apomixia e sua utilização no melhoramento de Brachiaria. In: Carneiro VTC, Dusi DMA (eds) Clonagem de plantas por sementes: estratégias de estudo da apomixia Embrapa Recursos Genéticos e Biotecnologia Brasília - DF, pp 47-65

Van Went JL, Willemse MTM (1984) Fertilization. In: Johri BM (ed) Embryology of angiosperms. Springer, Berlin, p 274

Warner JR, McIntosh KB (2009) How common are extraribosomal functions of ribosomal proteins? Mol Cell 34(1):3-11

Whittle C, Malik M, Li R, Krochko J (2009) Comparative transcript analyses of the ovule, microspore, and mature pollen in Brassica napus. Plant Mol Biol 72(3):279-299

Whittle CA, Krochko JE (2009) Transcript profiling provides evidence of functional divergence and expression networks among ribosomal protein gene paralogs in Brassica napus. Plant Cell 21 (8):2203-2219. doi:10.1105/tpc. 109.068411

Wool IG (1996) Extraribosomal functions of ribosomal proteins. Trends Biochem Sci 21(5):164-165

Yu X, Warner JR (2001) Expression of a micro-protein. J Biol Chem 276(36):33821-33825. doi:10.1074/jbc.M103772200 